Gut, 1962, 3, 80

\title{
The influence of sex and age on appendicitis in children and young adults
}

\author{
J. A. H. LEE \\ From the Social Medicine Research Unit (M.R.C.), London Hospital, \\ Whitechapel, London
}

SYNOPSIS A study has been made of the influence of age and sex on the incidence of cases of appendicitis and of fatal appendicitis in children and young adults. Appendicitis is uncommon in children under the age of 5 , but the proportion of cases complicated by peritonitis is large, and the death rate in the population of this age is relatively high. Appendicitis is very common in adolescents, but here the proportion of cases complicated by peritonitis is small. However, because of the frequency of the condition, the death rate in the general population of this age is high, with a maximum at about the age of 15 years.

These findings are compatible with the suggestion that the appendix during the 'teens is particularly liable to obstruct and hence to become inflamed because of the large proportion of lymphoid tissue which it contains.

Inflammation of the appendix is more common in males than in females, and this male excess is greater in infants and pre-school children than it is in children of school age.

Appendicitis is known to be commoner in adolescents than it is in either children or young adults and to be commoner in males than in females (cf. Love, 1947; Boyce, 1949a). The very large series of cases of all types of disease reported in the national Hospital In-patient Enquiry have made it possible to study the influence of age and sex on the incidence and fatality of appendicitis in greater detail than before. In this paper an attempt has been made to describe the complex changes that are found.

\section{METHOD}

The cases of appendicitis discussed here were derived from an effectively random sample of all the discharges from the majority of National Health Service hospitals during 1956 and 1957. The details of the way in which the sample was collected have been given in the report of the Enquiry (Ministry of Health and General Register Office, 1961). Where stated in the figures and tables, data collected in earlier years by the Enquiry have been included. Analyses were made by single years of age, or two-year age groups, as well as by the conventional five-year age groups. As an extension of the studies on morbidity, comparable data on mortality were obtained through the kindness of the General Register Office.

\section{RESULTS}

The numbers of cases described on discharge as suffering from appendicitis are shown, by sex and single years of age, in Fig. 1. A conspicuous feature of this diagram is the large number of cases reported in teenage girls and young women. These cases have been discussed in a separate paper (Lee, 1961). They are apparently benign and are different from appendicitis as it is usually understood. They will not be discussed further here, except in so far as they affect the present analyses.

In both sexes, there is from infancy a steady increase in the number of cases of appendicitis reported at successive years of age. This increase reaches a peak at the age of 12 in boys and 10 in girls. After that there is a steady decline in boys, and what appears to be the beginning of one in girls. The cases reported in the Enquiry as being complicated by peritonitis are shown in Fig. 2. The numbers of cases with peritonitis are high in children aged 4 to 5 in both sexes, and there is another peak at the age of 14 to 15 in boys (Fig. 2). The proportion of the total cases of appendicitis 


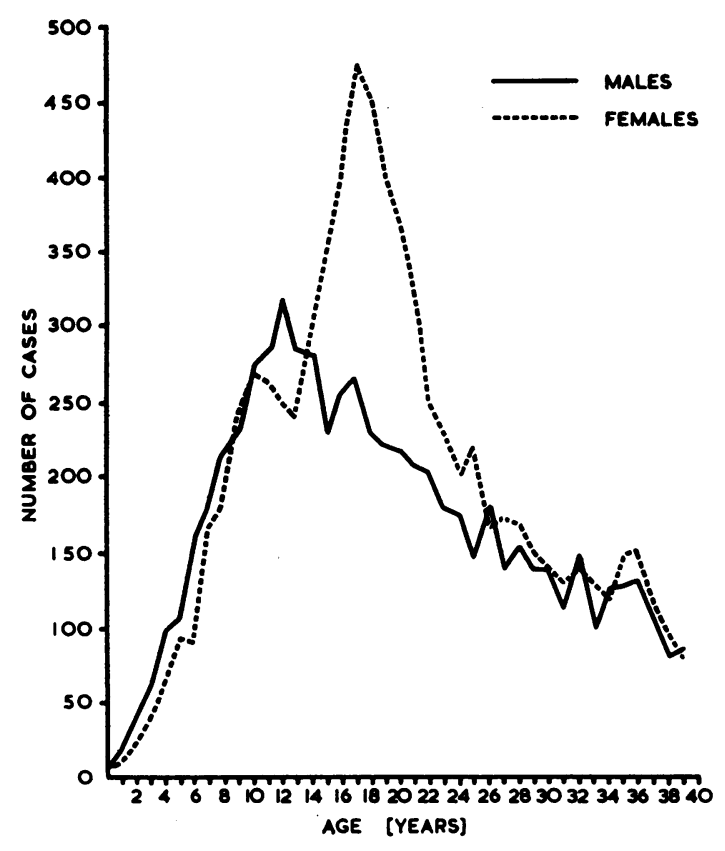

FIG. 1. Number of cases of all types of appendicitis in males and females by single years of age to 40 (Hospital In-patient Enquiry, 1956-57). Numbers corrected for variations in the population at risk (Lee, 1961).

complicated by peritonitis is high in young children, and then falls with increasing age in both sexes (Table I).

The death rate in the general population from appendicitis is high in young children, then declines to a minimum at the age of 8 to 9 (Fig. 3). A new rise then occurs in boys, which reaches a peak at the age of 14 to 15 years. In girls there is a small rise in the death rate at about this age which may represent a change corresponding to the one in boys.

The present relatively high death rates from appendicitis in pre-school children compared with children aged 5 to 9 have only developed in England and Wales in the post-war years. Before then, the

\section{TABLE I}

PROPORTION OF CASES OF APPENDICITIS COMPLICATED BY PERITONITIS BY AGE AND SEX : HOSPITAL IN-PATIENT ENQUIRY (1956-57)

Percentages

\begin{tabular}{lcccccc}
\hline Age & $0-$ & $5-$ & $10-$ & $15-$ & $20-$ & $25-29$ \\
Male & $22 \cdot 2$ & $8 \cdot 1$ & $5 \cdot 3$ & $4 \cdot 8$ & $5 \cdot 0$ & $6 \cdot 4$ \\
Female $^{1}$ & $22 \cdot 4$ & $8 \cdot 3$ & $4 \cdot 1$ & $(1 \cdot 6)$ & $(2 \cdot 2)$ & $(3 \cdot 0)$
\end{tabular}

${ }^{1}$ Percentages for females aged more than 15 are reduced by the excess of uncomplicated cases.

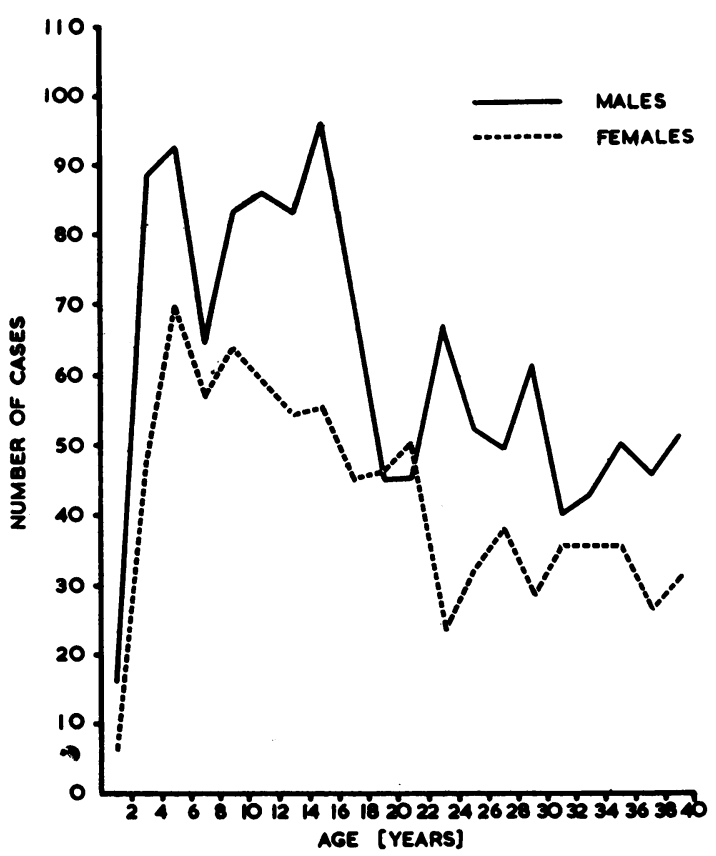

FIG. 2. Number of cases of appendicitis with peritonitis in males and females by two-year age groups to 40 (Hospital In-patient Enquiry, 1956-57).

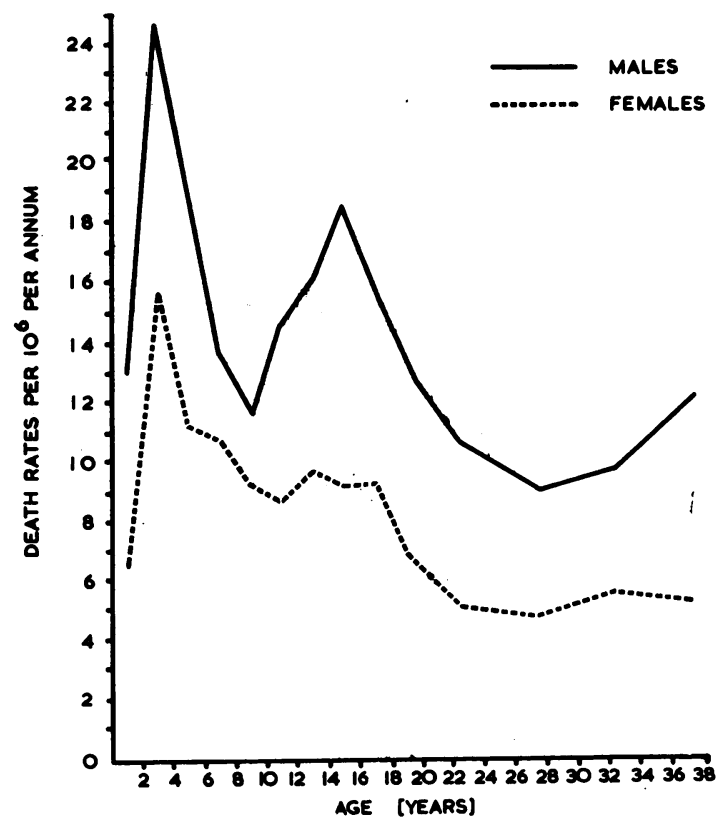

FIG. 3. Death rates from appendicitis in England and Wales from 1950-57, calculated for two-year age groups from 0 to 19 and for five-year age groups from 20 to 39 years. 
younger children had the lower rates (Fig. 4). At the end of the war, the death rate in the 5 to 9 age group declined faster than did the rate in the 1 to 4 age group in both sexes. Similar changes occurred in the United States, but these were about five years earlier, about 1940. Apparently the rather older children had a greater capacity to respond to some development in diagnosis or treatment that began at that time.

It is not possible to trace clearly over a number of years the trend in the high death rates in adolescents, for these are obscured by the conventional five-year age groups which are all that are obtainable before about 1950 (Table II). However, they appear to go back at least to 1930 .

Appendicitis is well known to be commoner in males than in females. The data reported here

\section{TABLE II}

COMPARISON OF EFFECT OF AGE ON DEATH RATES BASED ON TWO- AND FIVE-YEAR AGE GROUPS

Male Rates Per Million per Annum, England and Wales, 1950-57

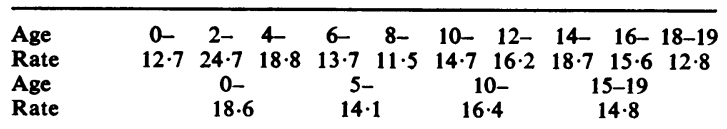

suggest that the male excess is smaller in school children than in young adults (Table III). This is so both in the cases complicated by peritonitis and the fatal ones. Appendicitis is no more likely to be complicated by peritonitis in boys than in girls (Table I), but there is no evidence as to what happens after 15 years of age. Part of the change in the sex

\section{TABLE III}

SEX RATIOS (MALE PATIENTS PER FEMALE) IN APPENDICITIS COMPLICATED BY PERITONITIS, AND IN FATAL APPENDICITIS, BY AGE ${ }^{1}$

\begin{tabular}{lcccccc} 
Age & $0-$ & $5-$ & $10-$ & $1.5-$ & $20-$ & $25-29$ \\
\hline $\begin{array}{l}\text { Appendicitis with } \\
\text { peritonitis }\end{array}$ & 1.6 & 1.2 & 1.4 & 1.7 & 1.6 & 1.8 \\
Fatal appendicitis & 1.7 & 1.4 & 1.7 & 1.9 & 2.0 & 1.9
\end{tabular}

${ }^{1}$ The cases are from the Hospital In-patient Enquiry 1956-57, the deaths are those that occurred in England and Wales, 1950-57. The ratios of the cases are based on the reported numbers, without correction for variations in the population at risk. While there are substantial variations in the population at risk from age to age (see Fig. 1), the sex ratio in the population at risk alters very little with age in young people. The ratios of the deaths are based on the death rates, and are thus corrected for differences in the population at risk. The sex ratios of the reported deaths in the age group 15 to 19 (where the effects of National Service will be felt) is $1 \cdot 82$, while the ratio of the death rates is 1.87 . Similarly at ages 0 to 4 , where there is a small male excess in the population, the ratio of the deaths is $1 \cdot 75$, and of the death rates is 1.67 . It is reasonable to suppose that differences in the population at risk have made no more difference to the sex ratios of the non-fatal cases. Again the uncertainty of diagnosis of uncomplicated appendicitis in females prevents the sex ratio being studied.

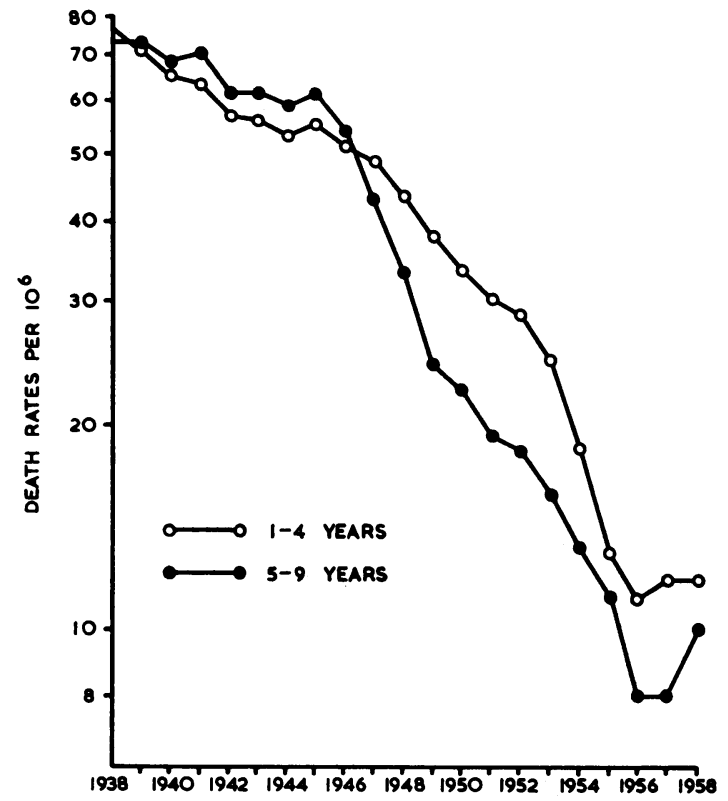

FIG. 4. Death rates from appendicitis in boys for England and Wales, 1938-58 (three-year moving means).

ratio of complicated appendicitis (Table III) at 15 may be because mature males with peritonitis are more likely to die than females (Table IV).

While an increased divergence between the sexes after the age of 15 might have been expected, there is evidence that the sex difference is greater in children aged less than 5 years than in school

\section{TABLE IV}

CASE FATALITY IN APPENDICITIS COMPLICATED BY PERITONITIS BY AGE AND SEX: HOSPITAL IN-PATIENT ENQUIRY $1951-57^{1}$

\begin{tabular}{|c|c|c|c|c|}
\hline Age & $0-14$ & $15-44$ & $55-64$ & $65+$ \\
\hline \multicolumn{5}{|l|}{ Male } \\
\hline Deaths & 19 & 17 & 21 & 33 \\
\hline Cases & 612 & 743 & 405 & 170 \\
\hline Case fatality & $3 \cdot 1 \%$ & $2 \cdot 3 \%$ & $5 \cdot 2 \%$ & $19 \cdot 4 \%$ \\
\hline \multicolumn{5}{|l|}{ Female } \\
\hline Deaths & 13 & 8 & 12 & 37 \\
\hline Cases & & 528 & 369 & \\
\hline Case fatality & $3 \cdot 2 \%$ & $1.5 \%$ & $3 \cdot 3 \%$ & $16.9 \%$ \\
\hline
\end{tabular}

${ }^{1} 1951$, 1955, and 1956-57 published by the General Register Office. No data collected by them during 1952. 1953-54 from unpublished tabulations.

children (Table III). There are too few cases for any smaller subdivision by age to be made, but the deaths from appendicitis in children under the age of 1 are reported separately in both the United States and England and Wales. The male excess of 
these infant deaths from appendicitis appears to be consistently greater than in older children (Table V).

\section{TABLE $\mathrm{V}$}

SEX RATIOS (MALE DeATH RATE : Female) IN FATAL APPENDICITIS IN INFANTS AND YOUNG CHILDREN IN ENGLAND AND WALES, 1945-57, AND UNITED STATES WHITES, 1950-55 AND 1956-571

\begin{tabular}{lrccc} 
Age & Under 1 & $1-4$ & $5-9$ \\
\hline England and Wales, $1945-57$ & 2.9 & $1 \cdot 7$ & 1.4 \\
United States, & $1950-55$ & 1.7 & 1.4 & 1.3 \\
& $1956-57$ & 1.7 & 1.1 & 1.5
\end{tabular}

${ }^{1}$ Appendicitis in infancy is rare, thus only 12 female deaths occurred in this period in England and Wales under the age of 1 year. In the United States there were 30 female infant deaths certified to this cause in 1950-55, and 11 in 1956-57.

\section{DISCUSSION}

In this series, as in others (e.g., Green and Watkins, 1946; Love, 1947), there were few cases of appendicitis reported in infants and pre-school children (Fig. 1). But the numbers reported as being complicated by peritonitis were higher than in older children (Fig. 2), and the proportion of cases occurring in these children that were complicated by peritonitis was large (Table I). In the general population of pre-school children the death rate from appendicitis was high (Fig. 3). It is not the frequency, but the seriousness of appendicitis at this age which is important. This has been commented on often, and ascribed, among other things, to the difficulties of diagnosis, the proportionately greater length of the appendix, and the lack of development of the omentum in young children (e.g., Hudson and Chamberlain, 1939; Boyce, 1949b and c; Bunton, 1953). But the present death rate in these small children is higher than in those who are a little older. This is new, and cannot be ascribed to permanent factors such as those mentioned above.

The high incidence of appendicitis in adolescents found in this series is also in agreement with earlier work. The percentage of cases complicated by peritonitis is not high, but the total number of cases is large. Hence, in contrast to the pre-school child, the high death rate among adolescents is probably due to the frequency of appendicitis rather than to its severity. The fatality of appendicitis is much reduced by early treatment, and the adolescent is not conspicuously careful of his health. It might therefore be thought that the high mortality from appendicitis in adolescents was due to delay. But if this were so, the proportion of adolescent cases complicated by peritonitis would be expected to be high, and there is no sign of this (Table I).
The maximum frequency of appendicitis with peritonitis, and of fatal appendicitis is at ages 14 to 15 , while the maximum frequency of the total cases of appendicitis is at age $12^{1}$. The peak of serious appendicitis is not clearly marked in girls, but a similar gap appears to exist. Non-specific mesenteric lymphadenitis is another common diagnosis in children, and from the lack of unanimity of the literature (cf. Aird, 1945; MacKeith and O'Neill, 1951; Ward-McQuaid, 1951; FitzGerald, 1956) its diagnosis and separation from appendicitis is clearly not easy. The maximum number of cases of mesenteric lymphadenitis was found in this series to occur at the age of 7 . It is possible that the real maximum of uncomplicated appendicitis is at age 15, and this has been depressed to the observed age of 12 by the addition of a proportion of cases of mesenteric adenitis. This suggestion is supported by the occurrence of the maximum frequency of cases of appendicitis confirmed by histological examination in the age group 15 to 19 (Bohrod, 1946; Green and Watkins, 1946; see also Eisele, Slee, and Hoffmann, 1956).

This study has shown in greater detail than before the way in which the incidence and outcome of appendicitis are related to age in young people. It has been suggested that the peak in the development of lymphoid tissue which occurs during adolescence leads to an increased liability of the appendix to obstruct, and so accounts for the high incidence of the disease. It is interesting that the peak in the death rate in adolescents has shifted down the age scale in recent years (Fig. 5). This may be compared with the steady trend towards earlier physical maturity in children and adolescents (Tanner, 1961). This proposition about appendicitis has been given its most full exposition by Bohrod (1946). The present data on the relationship between age and the frequency of appendicitis fit in well with this idea. But knowledge of the way in which the anatomy of the appendix changes with age in childhood as yet appears to be too rudimentary for this explanation of the peak in appendicitis incidence to be accepted as more than a working hypothesis. Thus apparently the only quantitative study of the proportion of the appendix which is composed of lymphoid tissue was based on 37 cases aged under 11 , and 39 cases aged 11 to 20 (Hwang and Krumbhaar, 1940). It is also well known that inflammation of the appendix is more common in males than in females, although the variations of this with age do not seem to have been reported before. There is even less anatomical knowledge on

${ }^{1}$ There are only sufficient deaths for analysis by two-year age groups to be useful, while there are in all age groups except infancy sufficient numbers of total cases to give reliable figures for single years of age. 


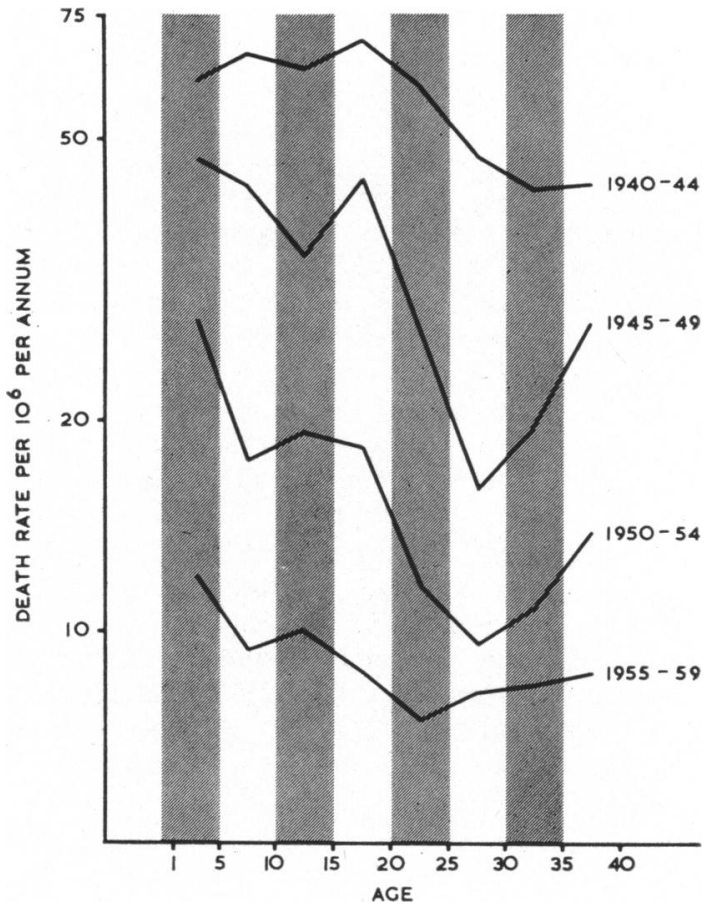

FIG. 5. Death rates from appendicitis in males for England and Wales, 1940-59.

which to base an interpretation of these changes than of the ones with age. Hwang and Krumbhaar (1940) found that the proportion of lymphoid tissue was higher in male appendices than in female, and that this difference persisted at all ages. This might well be an important observation, but again there is no confirmation. Why fatal appendicitis should be more rare in female infants than in male is particularly intriguing.

Appendicitis, although its consequence may be widespread, is usually believed to be by origin a local disease. One of the few well-authenticated features of appendicitis is that faecoliths predispose to rupture (Bowen, 1937; Bowers, 1939; Wakeley and Childs, 1950). But the prevalence of faecoliths at different stages of life, and in different groups of the population, is quite unknown. While it is not suggested that anatomical features can provide a complete explanation of the pathogenesis of appendicitis, the combination of theoretical considerations derived from Bohrod's suggestion and the direct evidence of the importance of faecoliths suggests that a better knowledge of the anatomy of the organ might explain some of the variations in the incidence of inflammation of it. Thus, for example, variations in the mean length or diameter or lumen size could well underlie the observed variations in the incidence of the disease.

More than 100,000 appendices are removed surgically every year in England and Wales (Ministry of Health and General Register Office, 1961) so there is no lack of material for study. However, these appendices have nearly all been removed at least on suspicion of being diseased, and conclusions founded on them would have to be checked by reference to appendices removed at necropsy that had given no evidence of disease in life.

I am grateful to the General Register Office of England and Wales for the tabulations of the data by single years of age. Professor J. N. Morris and my colleagues in the Social Medicine Research Unit and the London Hospital gave me much help.

\section{REFERENCES}

Aird, I. (1945). Acute non-specific mesenteric lymphadenitis. Brit. med.J., $2,680$.

Bohrod, M. G. (1946). The pathogenesis of acute appendicitis. Amer. J. clin. Path., 16, 752.

Bowen, W. H. (1937). Appendicitis: A clinical study, p. 25. University Press, Cambridge.

Bowers, W. F. (1939). Appendicitis, with especial reference to pathogenesis, bacteriology and healing. Arch. Surg. (Chicago), 39, 362.

Boyce, F. F. (1949a). Acute Appendicitis and its Complications, p. 335. Oxford University Press, New York. (1949b). lbid., p. 24.

- (1949c). Ibid., p. 335 et seq.

Bunton, G. L. (1953). Acute appendicitis in infancy and early childhood. Brit. med. J., $2,71$.

Eisele, C. W., Slee, V. N., and Hoffmann, R. G. (1956). Can the practice of internal medicine be evaluated? Ann. intern. Med., $44,144$.

FitzGerald, M. J. T. (1956). Non-specific mesenteric adentitis. Irish. J. Med. Sci., p. 205.

Green, H. W., and Watkins, R. M. (1946). Appendicitis in Cleveland. Surg. Gynec. Obstet., 83, 613 .

Hudson, H. W., and Chamberlain, J. W. (1939). Acute appendicitis in childhood, a statistical study of 848 cases from the Children's Hospital, Boston. J. Pediat., 15, 408.

Hwang, J. M. S., and Krumbhaar, E. B. (1940). The amount of lymphoid tissue of the human appendix and its weight at different age periods. Amer. J. med. Sci., 199, 75.

Lee, J. A. H. (1961). In the press.

Love, R. J. McNeill. (1947). The Appendix, p. 16. Lewis, London.

MacKeith, R., and O'Neill, D. (1951). Recurrent abdominal pain in children. Lancet, $2,278$.

Ministry of Health and General Register Office (1961). Report on Hospital In-patient Enquiry for the Two Years 1956-57. H.M.S.O., London.

Tanner, J. M. (1961) Education and Physical Growth, p. 113. University of London Press.

Wakeley, C., and Childs, P. (1950). Appendicitis. Brit. med. J., $2,1347$.

Ward-McQuaid, J. N. (1951). Acute non-specific mesenteric lymphadenitis; incidence and prognosis in children. Lancet, 2, 524 . 